\title{
CONCRETO PRODUZIDO COM AGREGADO GRAÚDO LATERÍTICO EM SANTARÉM, PARÁ
}

\author{
Concrete produced with lateritic coarse aggregate of Santarém, Pará State
}

Antonio Rodrigues Pantoja Junior ${ }^{1}$, Marcelo de Souza Picanço ${ }^{2}$

Recebido em 06 de janeiro de 2020; aceito em 12 de junho de 2020; disponível on-line em 04 de junho de 2020.

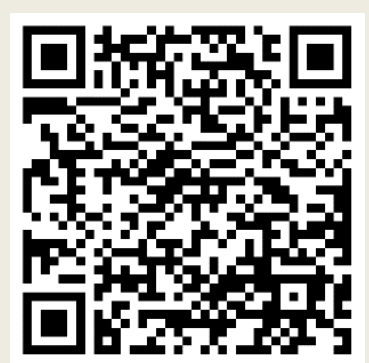

PALAVRAS CHAVE:

laterita;

resistência a compressão; materiais alternativos; tecnologia do concreto; economicidade.

\section{KEYWORDS:}

laterite;

compressive strength; alternative materials; concrete technology; economy.

\section{* Contato com os autores:}

${ }^{1}$ e-mail: antonio.pantoja@hotmail.com ( A. R. Pantoja Junior )

Eng. Civil, Mestre em Processos Construtivos e Saneamento Urbano, Programa de Pós-graduação do Instituto de Tecnologia da UFPA 2e-mail: marcelosp@ufpa.br ( M.S. Picanço)

Engenheiro Civil, Doutor em Geologia e Geoquímica, Coordenador de Pós-graduação, UFPA

\begin{abstract}
RESUMO: Avaliou-se a substituição da brita basáltica existente no concreto por material alternativo em abundância no município de Santarém-PA: a laterita. Foi avaliado o desempenho do concreto incorporado com agregado laterítico in natura em substituição parcial ao agregado graúdo de brita basáltica nos teores de $20 \%$ e $50 \%$. Realizou-se a caracterização dos agregados graúdo e miúdo. De acordo com o método da $A B C P$, determinou-se o traço de referência em massa 1:1,71:3,03:0,53; confeccionou-se corposde-prova cilíndricos $10 \times 20 \mathrm{~cm}$ utilizando 3 traços diferentes, de modo a substituir a brita basáltica pelo agregado laterítico, em $20 \%$ e $50 \%$. Para cada traço foram quantificados a sua consistência, por meio do ensaio de abatimento do tronco de cone, resistência à compressão axial, resistência à tração por compressão diametral e módulo de elasticidade aos 28 dias. A substituição do agregado convencional de brita basáltica por agregado laterítico em seu estado natural promoveu diminuição da resistência a compressão simples, da resistência à tração por compressão diametral e do módulo de elasticidade com a inclusão do agregado laterítico na mistura. Destaca-se que acima de determinado teor de substituição o concreto torna-se inviável devido a necessidade de adicionar aditivo plastificante para manter a consistência desejada e que as duas misturas incorporadas com agregado laterítico se mostraram muito semelhantes após os 28 dias, no que tange a ganhos de resistência a compressão.
\end{abstract}

ABSTRACT: This study is about the replacement of basaltic origin crushed stone by alternative material present in the municipality of Santarém, Pará State: the laterite. The aim were to evaluate the performance of concrete incorporated with natural lateritic aggregate, replacing the of crushed stone in $20 \%$ and $50 \%$. The first stage was characterizing the coarse and fine aggregates that made up the studied concrete. According to $A B C P$ dosing method it was determined the mass reference trait 1: 1.71: 3.03: 0.53; bodies of $10 \times 20 \mathrm{~cm}$ were made for cylindrical test, using three different strokes so that the basaltic crushed stone gradually replaced by the lateritic aggregate in proportions of $20 \%$ and $50 \%$. For each trait its consistency was quantified by means of the tapering test, axial compression strength, diametric compression tensile strength and the modulus of elasticity at 28 days. Was observed that the replacement of the conventional aggregate basalt crushed stone for aggregate of laterite in natural state promoted a decrease in the value of simple compressive strength, diametric tensile strength and modulus of elasticity with inclusion of a larger amount of lateritic aggregate in the mixture. It is noteworthy that above a certain substitution content, the concrete becomes not feasible due to the need for a large increase in the amount of plasticizer additive to the desired consistency is maintained and the two blends incorporated with lateritic showed very similar after 28 days in terms of gains in compressive strength.

Engenheiro Civil, Doutor em Geologia e Geoquímica, Coordenador de Pós-graduação, UFPA 


\section{INTRODUÇÃO}

A utilização de materiais alternativos na construção civil somente é possível quando os mesmos apresentam estudos científicos e vantagens econômicas que endossem sua utilização. Este binômio gera confiança, pode modificar hábitos culturais e, ao longo do tempo, estimular o uso de determinado material/insumo. Alguns poucos pesquisadores obtiveram resultados que estimulam o uso de concreções lateríticas como agregado graúdo alternativo para fabricação do concreto. De acordo com Chagas Filho (2005), as resistências obtidas foram inferiores àquelas obtidas para 0 concreto convencional de brita de rocha granítica, embora tenham atendido a condições de segurança em protótipos, vigas e lajes, testados em laboratório.

Os agregados graúdos desempenham um papel relevante na produção de concretos, seja do ponto de vista econômico ou técnico, pois ocupam até $80 \%$ do volume do concreto, influenciando significativamente sua resistência mecânica, estabilidade dimensional e durabilidade. Autores como Helene e Terzian (1992) e Calister (2002) afirmam que o agregado graúdo é essencial para a confecção de concretos com baixo custo, haja vista que o cimento é o constituinte mais caro dos mesmos. Para alguns estados da Região Norte a utilização da brita ou seixo rolado é impraticável devido à origem geológica das jazidas como, por exemplo, nos estados do Pará, Amazonas e Acre, onde a situação é mais crítica.

Segundo Chagas Filho (2005), laterita é uma argila endurecida, sem estratificação, extremamente porosa, rica em cavidades e que possui grande quantidade de ferro na forma de óxidos e hidróxidos de coloração amarelo avermelhada. No entanto, a laterita é vantajosa como produto alternativo por estar presente em solos de regiões tropicais e subtropicais da Terra. No território brasileiro, a laterita é encontrada nos solos ditos como latossolos, podzólico, terra roxa e solos lixiviados sob a floresta. Cerca de $40 \%$ das terras emersas do globo são recobertas por latossolos, e no Brasil, os latossolos recobrem em torno de $65 \%$ da área total do país. Entretanto, é quase inexistente sua utilização como insumo no concreto devido, ainda, ao pouco conhecimento científico tanto no meio técnico quanto acadêmico.

No Brasil há ocorrência de extensas áreas de formações lateríticas, principalmente na região norte, que podem representar fontes alternativas de agregados para emprego na construção civil. $\mathrm{Na}$ região amazônica, mais da metade da área é coberta por uma espessa camada de sedimentos quaternários e terciários não consolidados, sendo poucas as ocorrências de agregado natural. Outro agravante é o difícil acesso em determinadas áreas da região, afastadas dos centros consumidores e com severas restrições ambientais de exploração. Isso exige, muitas vezes, o transporte aquaviário de brita a distâncias que podem chegar a 3.000 $\mathrm{km}$, como em algumas cidades do Acre, utilizandose infraestrutura de transportes precária e ineficiente. Essa escassez de agregados gera um aumento considerável nos custos da construção civil na região, tornando economicamente atraente a produção de agregado com o uso de matéria-prima local.

Em Santarém, município do oeste do estado do Pará, essa regra não é diferente. Quase a totalidade da pedra britada consumida no mercado local para a produção de concreto é proveniente do município de Monte Alegre, distante cerca de $100 \mathrm{~km}$ de Santarém cujo transporte é realizado por meio de balsa por meio do rio Amazonas. Diante disso, é necessário que as propriedades de solos lateríticos sejam estudadas com a finalidade de aproveitar melhor tais materiais, diminuindo custos de construção onde o agregado convencional é escasso, ou exige grandes distâncias de transporte. $\mathrm{O}$ objetivo deste estudo consistiu em analisar a viabilidade técnica da utilização da laterita, em seu estado natural, como agregado graúdo, quando incorporada em teores de 20 e $50 \%$ na mistura do concreto, em substituição ao agregado graúdo convencional de brita basáltica. 


\section{REVISÃO DE LITERATURA}

\subsection{DOSAGEM DO CONCRETO}

A compatibilidade entre as características ótimas do concreto fresco para uma dada situação e aquelas exigidas após seu endurecimento não é facilmente obtida, conforme Helene \& Terzian (1993). Dessa forma, é fundamental conhecer as características dos materiais usados na composição do concreto para que se possa obter um equilíbrio entre o ótimo e o possível em sua concepção. Portando, dosar um concreto pode ser entendido como sendo o proporcionamento adequado e mais econômico possível de seus materiais constituintes. Para a presente pesquisa foram estudados alguns métodos experimentais de dosagem para a obtenção dos traços de concreto analisados, tais como: Método do IPTEPUSP, Método do INT e Método da $A B C P$, sendo este último adotado na pesquisa.

\subsubsection{Método da ABCP}

Esta metodologia de dosagem publicada pela Associação Brasileira de Cimento Portland (ABCP) apresenta característica experimental. Sendo uma adaptação do método americano proposto pela $\mathrm{ACl}$ (American Concrete Institute), considera tabelas e gráficos elaborados a partir de informações experimentais, que permitem a utilização dos agregados que se enquadram nos limites propostos pela norma NBR 7211:2009 Agregados para Concreto, da Associação Brasileira de Normas Técnicas (ABNT) (BOGGIO, 2000). O desenvolvimento do método obedece as seguintes etapas:

\subsubsection{Fixação da relação água / cimento $(\mathrm{a} / \mathrm{c})$}

A fixação deste parâmetro é feita tomando como referência os critérios de durabilidade e a resistência mecânica requerida pelo concreto nas idades de interesse. A resistência à compressão é o principal parâmetro da resistência mecânica a ser considerado. $O$ valor da relação água/cimento é estimado com base na curva de Abrams, que por sua vez, deve ser determinado em função do tipo de cimento. A quantidade de água necessária para que a mistura fresca adquira uma determinada consistência, medida pelo abatimento do tronco de cone, depende basicamente da granulometria, da forma e textura dos grãos, mais especificamente, da área específica do agregado total da mistura.

\subsubsection{Estimativa do consumo de cimento (C)}

Feita a estimativa do consumo de água por metro cúbico de concreto e adotada a relação água/cimento, a estimativa do consumo de cimento pode ser obtida pela equação a seguir:

$$
C=\frac{C_{a g}}{\left(\frac{a}{c}\right)}
$$

Em que:

$\mathbf{C}=$ Consumo de cimento por metro cúbico de concreto, em kg/m

Cag = Consumo de água por metro cúbico de concreto, em l/ $\mathrm{m}^{3}$;

$\mathrm{a} / \mathrm{c}=$ Relação água/cimento, em kg/kg.

\subsubsection{Estimativa do consumo de agregados}

A estimativa do Consumo do agregado graúdo por metro cúbico de concreto é dada pela equação:

$$
C_{p}=V_{p c} \cdot M U_{c}
$$

\section{Em que:}

$\boldsymbol{C}_{p}=$ Consumo do agregado graúdo por metro cubico de concreto, em $\mathrm{Kg} / \mathrm{m}^{3}$; $\boldsymbol{V}_{p c}=$ Volume compactado seco do agregado graúdo por metro cubico de concreto;

$\mathbf{M U}_{\boldsymbol{c}}=$ Massa unitária compactada do agregado graúdo por metro cúbico de concreto, em $\mathrm{kg} / \mathrm{m}^{3}$.

A estimativa do consumo do agregado miúdo (Ca), quando já determinados os consumos do cimento, água e agregado graúdo, é imediata. Isso se deve ao fato de que, por princípio, o volume de concreto é formado pela soma dos volumes absolutos dos materiais que $o$ constituem. 


\subsection{AGREGADOS}

Os agregados são materiais granulares, sem forma e volume definidos. Ocupam de 60 a $80 \%$ do volume total do concreto, portanto sua qualidade é de grande importância para a qualidade final do mesmo. As características dos agregados que mais se destacam para a fabricação do concreto são: porosidade, composição granulométrica, absorção de água, forma e textura superficial das partículas, resistência à compressão, módulo de elasticidade e os tipos de substâncias deletérias presentes. Essas características dos agregados influem nas propriedades do concreto. No estado fresco podem afetar sua coesão, consistência e trabalhabilidade e no estado endurecido a resistência à compressão, estabilidade dimensional, durabilidade, resistência à abrasão e aspecto visual. (ABCP, 2014).

\subsubsection{Classificação dos agregados}

\subsubsection{Quanto à origem}

Podem ser naturais: encontrados na natureza e podem requerem processos simples de lavagem ou seleção, como por exemplo areia e pedregulho; ou artificiais: materiais processados industrialmente, incluindo-se britagem, a partir de matérias-primas naturais, como por exemplo brita, pedrisco, argila expandida, EPS, concreto reciclado de demolições.

\subsubsection{Quanto à massa específica}

Podem ser classificados como leves: agregados com massa específica menor que 2000 $\mathrm{kg} / \mathrm{m}^{3}$, como por exemplo EPS, argila expandida, vermiculita; normais: agregados com massa específica entre $2000 \mathrm{~kg} / \mathrm{m}^{3}$ e $3000 \mathrm{~kg} / \mathrm{m}^{3}$, como as areias naturais de cava ou praia, pedras britadas, pedregulho; ou pesados: agregados com massa unitária acima de $3000 \mathrm{~kg} / \mathrm{m}^{3}$, a exemplo barita, magnetita, hematita.

\subsubsection{Quanto à dimensão dos grãos}

Podem ser classificados em miúdos: agregados cujos grãos passam pela peneira 4,75 $\mathrm{mm}$ e ficam retidos na peneira $150 \mu \mathrm{m}$, em ensaio realizado de acordo com a NBR NM 248 ou graúdos: agregados cujos grãos passam pela peneira $75 \mathrm{~mm}$ e ficam retidos na peneira $4,75 \mathrm{~mm}$, em ensaio realizado de acordo com a NBR NM 248.

\subsubsection{Composição Granulométrica}

A composição granulométrica de um agregado, obtida por peneiramento de acordo com a NBR NM 248:2003 e corresponde a distribuição das partículas do material entre várias dimensões presentes na amostra, sendo usualmente expressa em termos de porcentagens acumuladas ou individuais retidas nas peneiras da série normal e intermediária indicadas neste mesmo texto normativo.

\subsection{CIMENTO PORTLAND}

O Cimento Portland é um aglomerante hidráulico proveniente da moagem do chamado clínquer Portland. O clínquer é obtido pela mistura e moagem de calcário e argila em proporções adequadas. Esta mistura é aquecida em fornos (em geral rotativos) até temperaturas próximas da fusão completa do material, sofrendo um rápido resfriamento. 0 clínquer Portland é moído juntamente com gesso, resultando no Cimento Portland; um material em pó, fino e de cor acinzentada. A adição do gesso (gipsita), em proporções de massa de 3 a $5 \%$, é realizada na moagem final do cimento com o intuito de regular o tempo de pega, permitindo que o cimento permaneça trabalhável por um período de, pelo menos, uma hora. O cimento produzido desta forma constituise de vários óxidos que compõem compostos complexos que se combinam com a água. Esta combinação entre o cimento e água resulta em um material cristalino com propriedades de resistência e aderência aos agregados e às armaduras. 


\subsection{CONCRETO}

Concreto de Cimento Portland é o material mais utilizado na construção civil na atualidade. É constituído pela mistura de cimento, agregados inertes e água e, de forma eventual, por aditivos e adições conforme a necessidade. Este material passou a ser utilizado como é conhecido hoje no fim do século XIX, com uso intensificado em meados do século $X X$; quando o concreto se transformou no material mais utilizado do mundo, depois da água. A mistura de Cimento Portland e água forma uma pasta cuja fluidez varia conforme a relação água/cimento da combinação. Esta pasta envolve os agregados, produzindo um material que é capaz de se moldar aos mais variados formatos. Nas primeiras horas o concreto apresenta certa fluidez, dependendo das características da mistura, com o passar do tempo, a mistura endurece pela reação de caráter irreversível do cimento em contato com a água. Este adquire resistência mecânica tornando-se um material de grande utilidade estrutural, de acordo com Moreira (2004).

\section{MATERIAIS E MÉTODOS}

O estudo foi conduzido no município de Santarém, Pará. Foi empregado o traço de referência 1:1,71:3,03, calculado pelo método $A B C P$, com relação água/cimento de 0,53 , abatimento do tronco de cone de $70 \mathrm{~mm} \mathrm{e}$ resistência característica requerida de $20 \mathrm{MPa}$. Justifica-se o uso da resistência de projeto em virtude de ser a mais adotada nas obras civis no município em tela. A tabela 1 apresenta o proporcionamento dos materiais utilizados neste estudo. Sendo que para o presente estudo foi empregado o traço de referência 1:1,71:3,03, calculado pelo método $A B C P$, com relação água/cimento de 0,53 , abatimento do tronco de cone de $70 \mathrm{~mm}$ e resistência característica requerida de $20 \mathrm{MPa}$. Justifica-se o uso da resistência de projeto em virtude de ser a mais usual nas obras civis no município de Santarém. A Tabela 1 apresenta o proporcionamento dos materiais utilizados neste estudo.

A caracterização dos materiais e ensaios mecânicos de resistência à compressão e de resistência à tração por compressão diametral e foram realizados durante os meses de maio e junho de 2019 no Laboratório de Ensaios Tecnológicos do 8o Batalhão de Engenharia de Construção. A Figura 1 mostra esquematicamente o programa experimental, totalizando três diferentes composições de concreto para a realização dos ensaios de resistência à compressão axial (ABNT NBR 5739:2007) e resistência à tração por compressão diametral (ABNT NBR 7222:2011) nas idades de 3; 7 e 28 dias.

TABELA 1: Proporções dos materiais utilizados nos traços

\begin{tabular}{|c|c|c|c|c|}
\hline$\%$ LAT. & CIMENTO (kg) & AG. GRAÚDO (KG) & AG. MIÚDO (KG) & LATERITA (KG) \\
\hline $0 \%$ & 17,169 & 52,028 & 29,418 & 0 \\
\hline $20 \%$ & 17,169 & 41,623 & 29,418 & 10,405 \\
\hline $50 \%$ & 17,169 & 26,014 & 29,418 & 26,014 \\
\hline
\end{tabular}

FONTE: Autoria Própria 


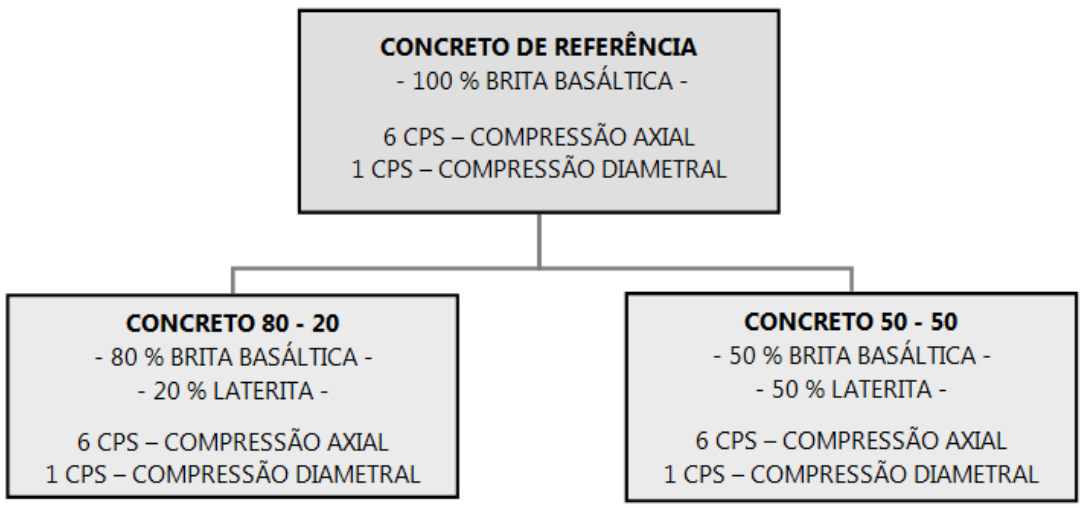

FIGURA 1: Programa experimental ensaios de resistência à compressão. FONTE: Autoria Própria

Utilizou-se cimento tipo portland composto com adição de material carbonático, tendo em vista o fato de ser amplamente adotado no município de Santarém. As características do cimento Portland estão no Quadro 1 e foram fornecidas pelo fabricante. Utilizou-se areia fina lavada adquirida como agregado miúdo e brita basáltica como agregado graúdo, ambas extraídas de jazidas localizadas em Itaituba - Pará e comercializadas em Santarém, no mercado local. O agregado graúdo também foi extraído em concreções lateríticas obtidas em jazida localizada a cerca de $20 \mathrm{~km}$ da cidade de Santarém, PA. Utilizouse ainda aditivo plastificante multidosagem
CEMIX 2010, da marca Vedacit e água fornecida por fonte de abastecimento própria do 8o BEC.

O estudo experimental está dividido em quatro etapas. A primeira consistiu na localização, coleta e transporte dos materiais ao laboratório, com posterior redução das amostras para a realização dos ensaios de caracterização. A segunda, na caracterização das propriedades físicas dos materiais para a produção do concreto laterítico e o concreto de referência. A terceira etapa consistiu no estudo de dosagem, produção do concreto e realização de ensaios no seu estado fresco e endurecido. Por fim, a quarta etapa análise e conclusão dos resultados.

QUADRO 1: Composição química e características físicas do cimento Portland utilizado

\begin{tabular}{|c|c|c|c|c|c|c|c|}
\hline \multicolumn{2}{|c|}{ COMPOSIÇÃo QUÍMICA } & \multicolumn{2}{c|}{ FINURA } & \multicolumn{2}{c|}{ TEMPO DE PEGA } & \multicolumn{2}{c|}{ RESISTÊNCIA A COMPRESSÃO (NBR 7215) } \\
\hline $\begin{array}{c}\text { Material } \\
\text { carbonático }\end{array}$ & $\begin{array}{c}\text { Clínquer + } \\
\text { sulfato de cálcio }\end{array}$ & $\begin{array}{c}\text { Resíduo na } \\
\text { peneira \# 75 }\end{array}$ & Início & Fim & $\mathbf{3}$ dias & $\mathbf{7}$ dias & $\mathbf{2 8}$ dias \\
\hline $11-25 \%$ & $75-89 \%$ & $\leq 12 \%$ & $\geq 60 \mathrm{~min}$ & $\leq 600 \mathrm{~min}$ & $\geq 10 \mathrm{MPa}$ & $\geq 20 \mathrm{MPa}$ & $\geq 32 \mathrm{MPa}$ \\
\hline
\end{tabular}




\subsection{Ensaios}

\subsubsection{Caracterização do agregado miúdo}

Para o agregado miúdo foram realizados ensaios de caracterização quanto as suas propriedades físicas, a fim de obter sua composição granulométrica segundo a NBR NM 248:2003, massa unitária (NBR NM 45:2006), determinação de massa específica conforme a norma NBR NM 52:2009 e determinação do teor de materiais pulverulentos (NBR NM 46:2003).

\subsubsection{Caracterização do agregado graúdo}

Para o agregado graúdo foram feitos ensaios de caracterização quanto as suas propriedades físicas a fim de obter sua composição granulométrica (NBR NM 248:2003), massa unitária (NBR NM 45:2006), massa específica (NBR NM 53: 2009), determinação do teor de materiais pulverulentos segundo a NBR NM 46:2003; avaliação do desgaste superficial dos grãos por meio do ensaio de abrasão Los Angeles (NBR NM 51:2001); avaliação da lamelaridade dos agregados através da determinação do índice de forma pelo método do paquímetro (NBR 7809:2008) e determinação do teor de argila em torrões e materiais friáveis (NBR 7218:2010).

\subsubsection{Ensaios de resistência à compressão axial.}

Os ensaios para determinação das resistências à compressão axial nas idades de 3,7 e 28 dias, foram realizados de acordo com a ABNT NBR 5739:2018. Utilizando-se moldes cilíndricos metálicos de dimensões $10,0 \mathrm{~cm} \times 20,0 \mathrm{~cm}$, seguindo as recomendações da ABNT NBR 5738:2016.

\subsubsection{Ensaios de resistência à tração por compressão diametral.}

Ensaios de Resistência à tração por compressão diametral na idade de 28 dias, conforme a ABNT NBR 7222:2011 - Determinação da resistência à tração por compressão diametral de corpos-de-prova cilíndricos. A resistência à tração foi calculada pela expressão:

$$
f_{c t, s p}=\frac{2 \cdot F}{\pi \cdot d \cdot l}
$$

Em que:

$\boldsymbol{f}_{c t, s p}=$ resistência à tração por compressão diametral, em MPa;

$\mathbf{F}=$ carga máxima obtida no ensaio, em $\mathrm{N}$;

$\mathbf{d}=$ diâmetro do corpo de prova, em $\mathrm{mm}$;

$I=$ altura do corpo de prova, em $\mathrm{mm}$.

\subsubsection{Módulo de elasticidade}

O módulo de elasticidade para cada amostra, na idade de 28 dias foi estimado de acordo com a ABNT NBR 6118 : 2014. Segundo esta norma, o módulo de deformação longitudinal depende da resistência à compressão do concreto $(f c)$, e pode ser estimado satisfatoriamente pela Equação (4).

$$
E=5600 \cdot f_{c}^{1 / 2}
$$

\subsubsection{Parâmetro de dosagem e nomenclaturas dos testemunhos}

A resistência característica do concreto adotada na pesquisa foi de $20 \mathrm{MPa}$. O traço em massa, calculado pelo Método da $A B C P$, com base nos ensaios de caracterização dos materiais foi 1 : 1,71: 3,03, com relação a/c 0,53 e abatimento do tronco de cone de $70 \mathrm{~mm}$.

O Quadro 2 contempla a nomenclatura adotada no estudo para a realização dos ensaios de resistência compressão axial, tração por compressão diametral e módulo de elasticidade do concreto.

\begin{tabular}{|c|c|}
\hline \multicolumn{2}{|c|}{ QUADRO 2: Nomenclatura adotada no estudo. } \\
\hline $\begin{array}{c}\text { NOMENCLATURA } \\
\text { ADOTADA }\end{array}$ & DESCRIÇÃO \\
\hline CR & $\begin{array}{r}\text { REFERÊNCIA - CR } \\
\text { (100\% BASALTO) }\end{array}$ \\
\hline CL 20 & $\begin{array}{c}\text { CONCRETO LATERÍTICO - CL 20 } \\
\text { (80\% BASALTO / 20 \% LATERITA) }\end{array}$ \\
\hline CL 50 & $\begin{array}{c}\text { CONCRETO LATERÍTICO - CL 50 } \\
\text { (50\% BASALTO / 50 \% LATERITA) }\end{array}$ \\
\hline
\end{tabular}

FONTE: Autoria Própria

\section{RESULTADOS E ANÁLISES}

\subsection{CARACTERIZAÇÃO DOS MATERIAIS}

\subsubsection{Cimento}

Foi utilizado cimento do tipo CP II F - 32 da 
marca NASSAU. A massa específica do cimento é de $3100 \mathrm{~kg} / \mathrm{m}^{3}$, conforme informações técnicas do fabricante.

\subsubsection{Caracterização do Agregado miúdo}

A Tabela 2 mostra o resultado da composição granulomética da areia natural utilizada na pesquisa.

A Figura 2 mostra a curva granulométrica. Observa-se que o agregado apresenta, de acordo com as especificações da NBR 7211 (ABNT, 2009), curva granulométrica parcialmente fora dos limites da zona utilizável.

\begin{tabular}{|c|c|c|c|c|c|c|}
\hline \multirow{2}{*}{$\begin{array}{l}\text { PENEIRAS } \\
(\mathrm{mm})\end{array}$} & \multicolumn{2}{|c|}{ MASSA RETIDA (g) } & \multicolumn{2}{|c|}{ MASSA RETIDA (\%) } & \multirow{2}{*}{$\begin{array}{l}\text { MASSA RETIDA } \\
\text { MÉDIA (\%) }\end{array}$} & \multirow{2}{*}{$\begin{array}{l}\text { MASSA RETIDA } \\
\text { ACUMULADA (\%) }\end{array}$} \\
\hline & ENSAIO A & ENSAIO B & ENSAIO A & ENSAIO B & & \\
\hline 25 & 0,0 & 0,0 & $0,0 \%$ & $0,0 \%$ & $0,0 \%$ & $0,0 \%$ \\
\hline 19 & 0,0 & 0,0 & $0,0 \%$ & $0,0 \%$ & $0,0 \%$ & $0,0 \%$ \\
\hline 12,5 & 0,0 & 0,0 & $0,0 \%$ & $0,0 \%$ & $0,0 \%$ & $0,0 \%$ \\
\hline 9,5 & 0,0 & 0,0 & $0,0 \%$ & $0,0 \%$ & $0,0 \%$ & $0,0 \%$ \\
\hline 6,3 & 0,0 & 0,0 & $0,0 \%$ & $0,0 \%$ & $0,0 \%$ & $0,0 \%$ \\
\hline 4,75 & 0,0 & 0,0 & $0,0 \%$ & $0,0 \%$ & $0,0 \%$ & $0,0 \%$ \\
\hline 2,36 & 1,0 & 1,0 & $0,1 \%$ & $0,1 \%$ & $0,1 \%$ & $0,1 \%$ \\
\hline 1,18 & 5,8 & 6,8 & $0,6 \%$ & $0,7 \%$ & $0,6 \%$ & $0,7 \%$ \\
\hline 0,6 & 53,4 & 50,1 & $5,3 \%$ & $5,0 \%$ & $5,2 \%$ & $5,9 \%$ \\
\hline 0,3 & 658,5 & 629,9 & $65,9 \%$ & $62,9 \%$ & $64,4 \%$ & $70,3 \%$ \\
\hline 0,15 & 256,2 & 289,1 & $25,6 \%$ & $28,8 \%$ & $27,2 \%$ & $97,5 \%$ \\
\hline Fundo & 24,9 & 25,2 & $2,5 \%$ & $2,5 \%$ & $2,5 \%$ & $100,0 \%$ \\
\hline
\end{tabular}

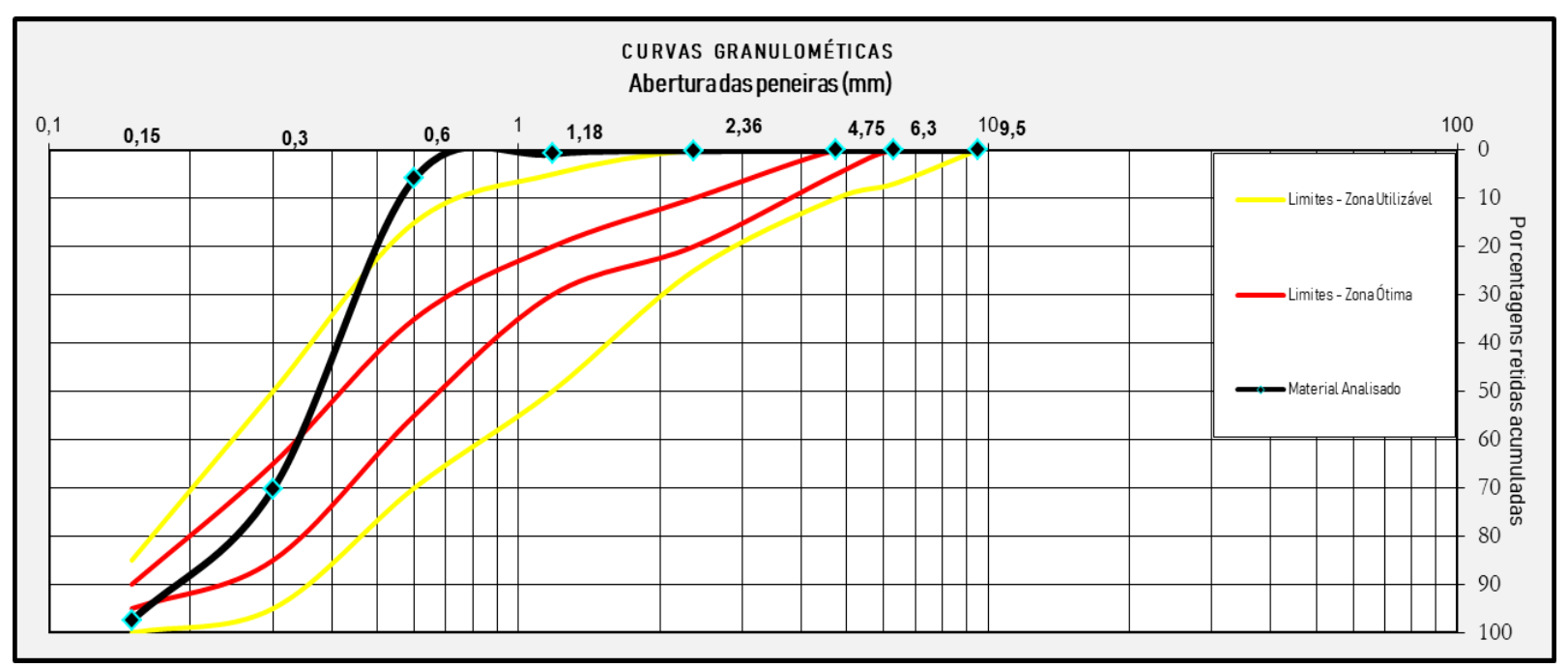

FIGURA 2: Curva granulométrica do agregado miúdo.

FONTE: Autoria Própria 
Na Tabela 3 está representado o resumo dos ensaios de caracterização do agregado miúdo.

4.1.3 Caracterização do agregado graúdo - brita basáltica

A Tabela 4 mostra os resultados da composição granulométrica da brita utilizada na pesquisa.
A Figura 3 mostra sua curva granulométrica. Observa-se que o agregado apresenta granulometria uniforme, e de acordo as especificações da NBR 7211 (ABNT, 2009), se enquadra na faixa correspondente a brita $\mathrm{n}$ - 1 .

A Tabela 5 representa um resumo dos ensaios de caracterização do agregado graúdo brita.

\begin{tabular}{|c|c|c|}
\hline \multicolumn{2}{|c|}{ TABELA 3: Caracterização do agregado miúdo. } \\
\hline SAIO REALIZADO & NORMA PERTINENTE & RESULTADO \\
\hline DIÂMETRO MÁXIMO CARACTERÍSTICO & ABNT NBR NM 248: 2003 & $1,18 \mathrm{~mm}$ \\
\hline MÓDULO DE FINURA & ABNT NBR NM 248: 2003 & 1,74 \\
\hline MASSA ESPECÍFICA & ABNT NBR NM $52: 2009$ & $2.589,33 \mathrm{~kg} / \mathrm{m}^{3}$ \\
\hline MASSA UNITÁRIA & ABNT NBR NM 45: 2006 & $1.513,00 \mathrm{Kg} / \mathrm{m}^{3}$ \\
\hline TEOR MAT. PULVERULENTO & ABNT NBR NM $46: 2003$ & $1,77 \%$ \\
\hline
\end{tabular}

FONTE: Autoria Própria

\begin{tabular}{|c|c|c|c|c|c|c|}
\hline & & A 4: Com & sição gra & ométrica & brita. & \\
\hline \multirow{2}{*}{$\begin{array}{l}\text { PENEIRAS } \\
(\mathrm{mm})\end{array}$} & \multicolumn{2}{|c|}{ MASSA RETIDA (g) } & \multicolumn{2}{|c|}{ MASSA RETIDA (\%) } & \multirow{2}{*}{$\begin{array}{l}\text { MASSA RETIDA } \\
\text { MÉDIA (\%) }\end{array}$} & \multirow{2}{*}{$\begin{array}{r}\text { MASSA RETIDA } \\
\text { ACUMULADA } \%\end{array}$} \\
\hline & ENSAIO A & ENSAIO B & ENSAIO A & ENSAIO B & & \\
\hline 75 & 0,0 & 0,0 & $0,0 \%$ & $0,0 \%$ & $0,0 \%$ & $0,0 \%$ \\
\hline 63 & 0,0 & 0,0 & $0,0 \%$ & $0,0 \%$ & $0,0 \%$ & $0,0 \%$ \\
\hline 50 & 0,0 & 0,0 & $0,0 \%$ & $0,0 \%$ & $0,0 \%$ & $0,0 \%$ \\
\hline 37,5 & 0,0 & 0,0 & $0,0 \%$ & $0,0 \%$ & $0,0 \%$ & $0,0 \%$ \\
\hline 31,5 & 0,0 & 0,0 & $0,0 \%$ & $0,0 \%$ & $0,0 \%$ & $0,0 \%$ \\
\hline 25 & 0,0 & 0,0 & $0,0 \%$ & $0,0 \%$ & $0,0 \%$ & $0,0 \%$ \\
\hline 19 & 109,3 & 129,0 & $5,4 \%$ & $6,4 \%$ & $5,9 \%$ & $5,9 \%$ \\
\hline 12,5 & $1.075,0$ & $1.035,2$ & $53,5 \%$ & $51,7 \%$ & $52,6 \%$ & $58,5 \%$ \\
\hline 9,5 & 488,1 & 507,2 & $24,3 \%$ & $25,3 \%$ & $24,8 \%$ & $83,3 \%$ \\
\hline 6,3 & 159,1 & 224,6 & $7,9 \%$ & $11,2 \%$ & $9,6 \%$ & $92,9 \%$ \\
\hline 4,75 & 37,4 & 31,2 & $1,9 \%$ & $1,6 \%$ & $1,7 \%$ & $94,6 \%$ \\
\hline 2,36 & 36,2 & 24,9 & $1,8 \%$ & $1,2 \%$ & $1,5 \%$ & $96,1 \%$ \\
\hline 1,18 & 29,9 & 12,8 & $1,5 \%$ & $0,6 \%$ & $1,1 \%$ & $97,2 \%$ \\
\hline 0,6 & 18,1 & 6,7 & $0,9 \%$ & $0,3 \%$ & $0,6 \%$ & $97,8 \%$ \\
\hline 0,3 & 15,0 & 7,1 & $0,7 \%$ & $0,4 \%$ & $0,5 \%$ & $98,3 \%$ \\
\hline 0,15 & 15,0 & 8,2 & $0,7 \%$ & $0,4 \%$ & $0,6 \%$ & $98,9 \%$ \\
\hline Fundo & 27,1 & 17,1 & $1,3 \%$ & $0,9 \%$ & $1,1 \%$ & $100,0 \%$ \\
\hline
\end{tabular}

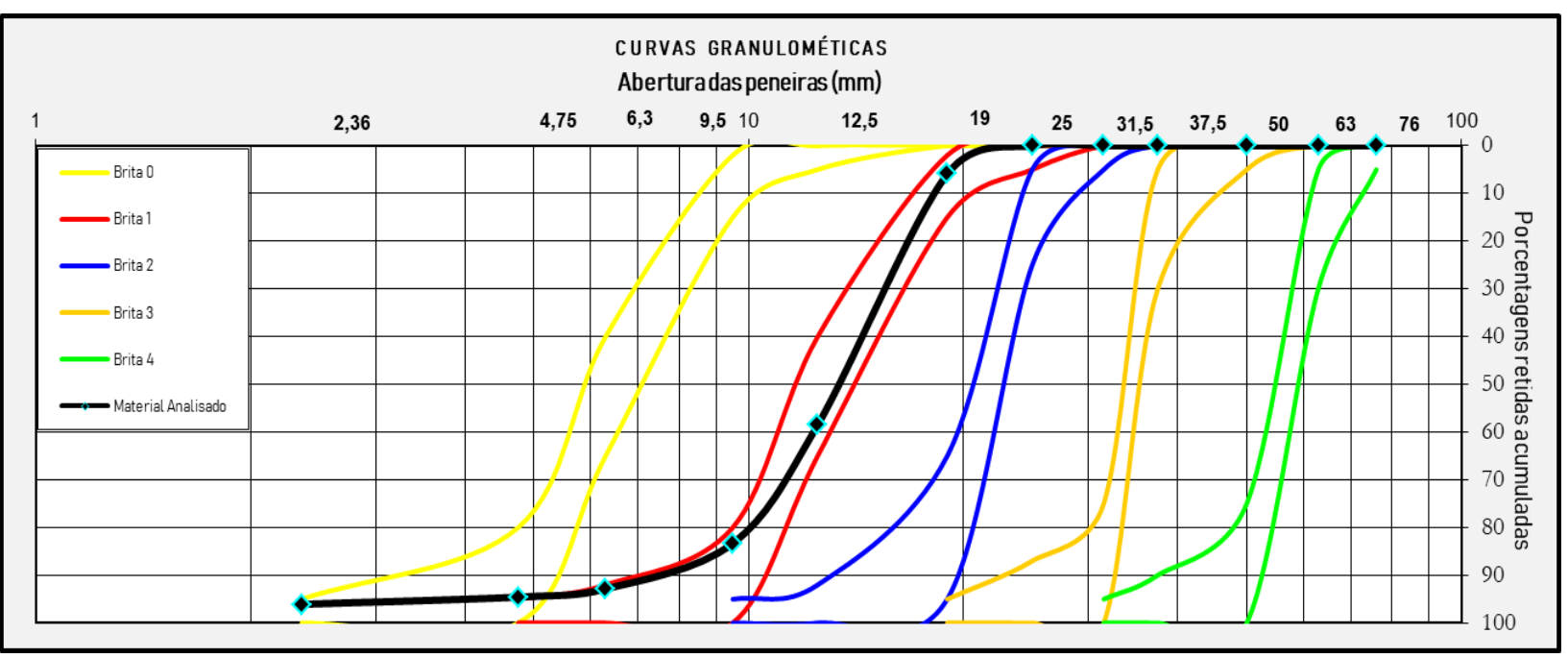

FIGURA 3: Curva granulométrica do agregado graúdo - brita.

FONTE: Autoria Própria 


\begin{tabular}{|c|c|c|}
\hline \multicolumn{4}{|c|}{ TABELA 5: Caracterizac̃a do agregado graúdo - brita } \\
\hline ENSAIO REALIZADO & NORMA PERTINENTE & RESULTADO \\
\hline DIÂMETRO MÁX. CARACTERÍSTICO & ABNT NBR NM 248: 2003 & $19 \mathrm{~mm}$ \\
\hline MÓDULO DE FINURA & ABNT NBR NM 248: 2003 & 6,72 \\
\hline MASSA ESPECÍFICA & ABNT NBR NM $53: 2009$ & $2.667,87 \mathrm{Kg} / \mathrm{m}^{3}$ \\
\hline MASSA UNITÁRIA & ABNT NBR NM 45: 2006 & $1.473,56 \mathrm{Kg} / \mathrm{m}^{3}$ \\
\hline TEOR MAT. PULVERULENTO & ABNT NBR NM 46: 2003 & $0,99 \%$ \\
\hline TEOR DE ARGILA E MAT. FRIÁVEIS & ABNT NBR 7218: 2010 & $0,27 \%$ \\
\hline ABRASÃO LOS ANGELES & ABNT NBR NM $51: 2001$ & $26 \%$ \\
\hline INDICE DE FORMA & ABNT NBR 7809: 2008 & 2,2 \\
\hline
\end{tabular}

FONTE: Autoria Própria

\subsubsection{Caracterização do agregado graúdo - laterita}

A laterita foi extraída de jazida localizada na área rural de Santarém e seu uso tanto nos ensaios de caracterização como na produção do concreto laterítico foram em sua forma natural. A Tabela 6 mostra os resultados da composição granulométrica da laterita utilizada na pesquisa.
A Figura 4 representa sua curva granulométrica. 0 agregado apresenta granulometria contínua, e de acordo as especificações da NBR 7211 (ABNT, 2009), sua curva granulométrica não se enquadra em nenhuma das cinco das 5 faixas granulométricas, apenas corta a faixa correspondente a brita no 0 .

\begin{tabular}{|c|c|c|c|c|c|c|}
\hline \multirow{2}{*}{$\begin{array}{l}\text { PENEIRAS } \\
(\mathrm{mm})\end{array}$} & \multicolumn{2}{|c|}{ MASSA RETIDA (g) } & \multicolumn{2}{|c|}{ MASSA RETIDA (\%) } & \multirow{2}{*}{$\begin{array}{l}\text { MASSA RETIDA } \\
\text { MÉDIA (\%) }\end{array}$} & \multirow{2}{*}{$\begin{array}{l}\text { MASSA RETIDA } \\
\text { ACUMULADA (\%) }\end{array}$} \\
\hline & ENSAIO A & ENSAIO B & ENSAIO A & ENSAIO B & & \\
\hline 75 & 0,0 & 0,0 & $0,0 \%$ & $0,0 \%$ & $0,0 \%$ & $0,0 \%$ \\
\hline 63 & 0,0 & 0,0 & $0,0 \%$ & $0,0 \%$ & $0,0 \%$ & $0,0 \%$ \\
\hline 50 & 0,0 & 0,0 & $0,0 \%$ & $0,0 \%$ & $0,0 \%$ & $0,0 \%$ \\
\hline 37,5 & 0,0 & 0,0 & $0,0 \%$ & $0,0 \%$ & $0,0 \%$ & $0,0 \%$ \\
\hline 31,5 & 0,0 & 0,0 & $0,0 \%$ & $0,0 \%$ & $0,0 \%$ & $0,0 \%$ \\
\hline 25 & 25,8 & 0,0 & $1,3 \%$ & $0,0 \%$ & $0,6 \%$ & $0,6 \%$ \\
\hline 19 & 24,2 & 36,2 & $1,2 \%$ & $1,8 \%$ & $1,5 \%$ & $2,2 \%$ \\
\hline 12,5 & 163,2 & 180,8 & $8,2 \%$ & $9,0 \%$ & $8,6 \%$ & $10,7 \%$ \\
\hline 9,5 & 181,8 & 213,9 & $9,1 \%$ & $10,7 \%$ & $9,9 \%$ & $20,6 \%$ \\
\hline 6,3 & 384,4 & 393,0 & $19,2 \%$ & $19,6 \%$ & $19,4 \%$ & $40,0 \%$ \\
\hline 4,75 & 294,6 & 292,8 & $14,7 \%$ & $14,6 \%$ & $14,7 \%$ & $54,7 \%$ \\
\hline 2,36 & 372,8 & 322,2 & $18,6 \%$ & $16,1 \%$ & $17,4 \%$ & $72,1 \%$ \\
\hline 1,18 & 245,6 & 225,9 & $12,3 \%$ & $11,3 \%$ & $11,8 \%$ & $83,8 \%$ \\
\hline 0,6 & 132,4 & 135,6 & $6,6 \%$ & $6,8 \%$ & $6,7 \%$ & $90,5 \%$ \\
\hline 0,3 & 74,7 & 83,8 & $3,7 \%$ & $4,2 \%$ & $4,0 \%$ & $94,5 \%$ \\
\hline 0,15 & 44,3 & 53,1 & $2,2 \%$ & $2,7 \%$ & $2,4 \%$ & $96,9 \%$ \\
\hline Fundo & 58,6 & 65,0 & $2,9 \%$ & $3,2 \%$ & $3,1 \%$ & $100,0 \%$ \\
\hline
\end{tabular}

FONTE: Autoria Própria 


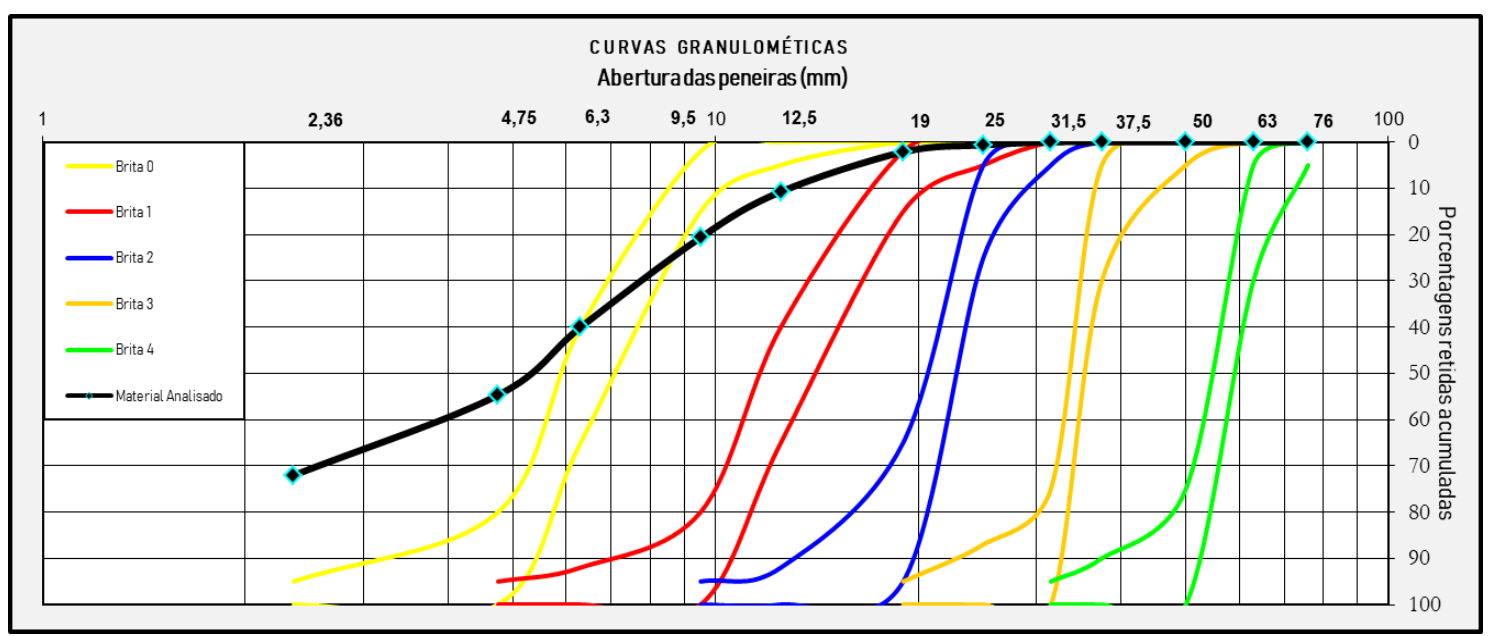

FIGURA 4: Curva granulométrica do agregado graúdo - laterita.

FONTE: Autoria Própria

Na tabela 7 estão representados os ensaios de caracterização da laterita.

\begin{tabular}{|c|c|c|}
\hline ENSAIO REALIZADO & NORMA PERTINENTE & RESULTADO \\
\hline $\begin{array}{l}\text { DIÂMETRO MÁX. } \\
\text { CARACTERISTICO }\end{array}$ & ABNT NBR NM 248: 2003 & $19 \mathrm{~mm}$ \\
\hline MÓDULO DE FINURA & ABNT NBR NM 248: 2003 & 5,15 \\
\hline MASSA ESPECCÍFICA & ABNT NBR NM 53: 2009 & $2.163,39 \mathrm{Kg} / \mathrm{m}^{3}$ \\
\hline MASSA UNITÁRIA & ABNT NBR NM 45: 2006 & $1.170,12 \mathrm{Kg} / \mathrm{m}^{3}$ \\
\hline $\begin{array}{c}\text { TEOR MAT. } \\
\text { PULVERULENTO }\end{array}$ & ABNT NBR NM 46: 2003 & $14,75 \%$ \\
\hline $\begin{array}{l}\text { TEOR DE ARGILA E } \\
\text { MAT. FRIÁVEIS }\end{array}$ & ABNT NBR 7218: 2010 & $16,47 \%$ \\
\hline $\begin{array}{l}\text { ABRASÃO LOS } \\
\text { ANGELES }\end{array}$ & ABNT NBR NM 51: 2001 & $35 \%$ \\
\hline INDICE DE FORMA & ABNT NBR 7809: 2008 & 1,9 \\
\hline
\end{tabular}

FONTE: Autoria Própria

\subsection{ENSAIOS}

\subsubsection{Resistência ao desgaste: Abrasão Los Angeles - laterita}

Buscou-se por meio do ensaio determinar a resistência ao desgaste superficial dos grãos do agregado graúdo, quando submetidos ao atrito por meio de carga abrasiva composta por esferas metálicas padronizadas. Para a laterita foi considerado, para a obtenção da amostra, a faixa $C$, com frações de $2,5 \mathrm{~kg}$ de material retido nas peneiras $6,3 \mathrm{~mm}$ e 4,75 $\mathrm{mm}$. Conforme recomendações da norma ABNT-NM-51:2001.

\subsubsection{Mistura, moldagem e cura dos corpos-de- prova cilíndricos}

Após a secagem dos agregados foi realizada a mistura dos materiais com betoneira de 150 litros, posteriormente a moldagem e adensamento dos corpos-de-prova cilíndricos para os ensaios de resistência a compressão axial e de tração por compressão diametral, após 24 horas foram desformados e armazenados em câmara úmida à temperatura de $(23 \pm 2){ }^{\circ} \mathrm{C}$ e umidade relativa do ar superior a 95\% conforme recomendações da NBR 5738 (ABNT, 2003). Na produção do concreto laterítico, afim de se obter consistência próxima a adotada na dosagem do concreto de referência, fez-se uso, no concreto $\mathrm{CL}$ 20 e CL 50, do aditivo plastificante CEMIX 2010 da VEDACIT nas proporções de $1,1 \%$ e $2,7 \%$, respectivamente, sobre a massa do cimento. Haja vista que ambos os traços se apresentaram extremamente secos e pouco trabalháveis mantendo-se a mesma relação $a / c$ do concreto de referência.

\subsubsection{Ensaios do Concreto no Estado Plástico}

Após a mistura dos materiais na betoneira foi realizado o ensaio de abatimento do tronco de cone conforme a NBR NM 67:1998 para os três concretos (referência, laterítico CL 20 e laterítico $\mathrm{CL}$ 50). A Tabela 8 apresenta os resultados dos ensaios de abatimento do tronco de cone do concreto: CR; CL 20 e CL 50. 


\begin{tabular}{|c|c|}
\hline \multicolumn{2}{|c|}{ TABELA 8: Resultados do abatimento do tronco do cone } \\
\hline TRAÇO & ABATIMENTO (mm) \\
\hline $\begin{array}{c}\text { REFERENCIA - CR } \\
(100 \% \text { BASALTO) }\end{array}$ & $50 \mathrm{~mm}$ \\
\hline $\begin{array}{c}\text { CONCRETO LATERÍTICO CL 20 (80\% } \\
\text { BASALTO / 20\% LATERITA) }\end{array}$ & $55 \mathrm{~mm}$ \\
\hline $\begin{array}{c}\text { CONCRETO LATERÍTICO CL } 50 \text { (50\% } \\
\text { BASALTO / 50\% LATERITA) }\end{array}$ & $60 \mathrm{~mm}$ \\
\hline
\end{tabular}

FONTE: Autoria Própria

\subsubsection{Ensaios do Concreto no Estado Endurecido}

A resistência à compressão é a propriedade mais importante no estudo do concreto, mas neste estudo também foram avaliadas outras propriedades como a resistência à tração indireta por compressão diametral e o módulo de elasticidade.

\subsubsection{Resistência à Compressão Axial}

Foram moldados corpos-de-prova cilíndricos de $10 \times 20 \mathrm{~cm}$ e rompidos nas idades de 3,7 e 28 dias contados a partir da data de moldagem. Os ensaios de resistência à compressão axial seguiram conforme a NBR 5739 (ABNT, 2018). A Figura 5 mostra o término do ensaio de compressão axial e a forma de ruptura dos corpos-de-prova.

A Tabela 9 e a figura 6 mostram os resultados da resistência à compressão do concreto na idade de 3 dias após a moldagem. Nota-se a semelhança entre os valores de resistências a compressão, do concreto laterítico CL-20 com o CL 50.
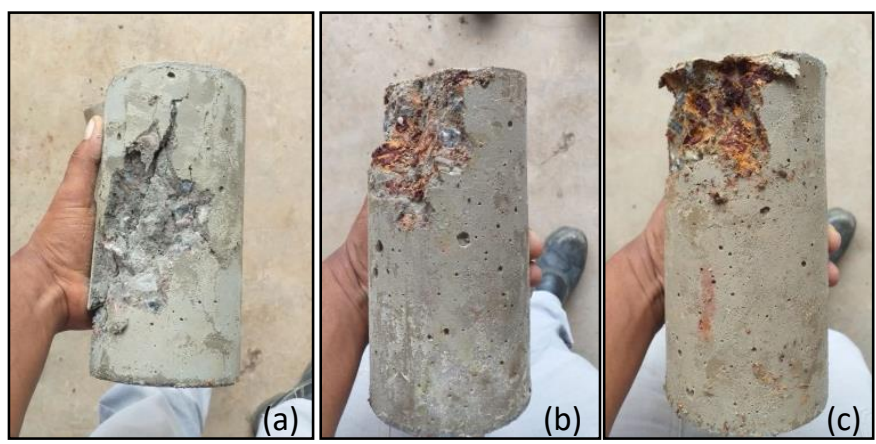

FIGURA 5: Após ensaio de compressão axial, (a) concreto de referência - CR, (b) Concreto laterítico - CL 20, (c) Concreto laterítico - CL 50,

FONTE: Autoria Própria

\begin{tabular}{|c|c|c|c|c|}
\hline TRAÇO & $\mathrm{CP}$ & $\begin{array}{c}\text { RESISTÊNCIA A } \\
\text { COMPRESSÃO (MPa) }\end{array}$ & $\begin{array}{c}\text { RESISTÊNCIA A COMPRESSÃO - } \\
\text { MÉDIA ARITIMÉTICA (MPa) }\end{array}$ & $\begin{array}{l}\text { DESVIO } \\
\text { PADRÃO }\end{array}$ \\
\hline \multirow{2}{*}{$\begin{array}{l}\text { REFERÊNCIA - CR } \\
(100 \% \text { BASALTO) }\end{array}$} & $\mathrm{CP} 1$ & 15.92 & \multirow{2}{*}{15.43} & \multirow{2}{*}{0.69} \\
\hline & CP 2 & 14.94 & & \\
\hline \multirow{2}{*}{$\begin{array}{l}\text { CONCRETO LATERÍTICO CL } 20 \text { (80\% } \\
\text { BASALTO / 20\% LATERITA) }\end{array}$} & CP 1 & 8.89 & \multirow{2}{*}{9.06} & \multirow{2}{*}{0.24} \\
\hline & CP 2 & 9,23 & & \\
\hline \multirow{2}{*}{$\begin{array}{l}\text { CONCRETO LATERÍTICO CL } 50 \text { (50\% } \\
\text { BASALTO / 50\% LATERITA) }\end{array}$} & CP 1 & 9.72 & \multirow{2}{*}{10.35} & \multirow{2}{*}{0.89} \\
\hline & CP 2 & 10.98 & & \\
\hline
\end{tabular}

FONTE: Autoria Própria 


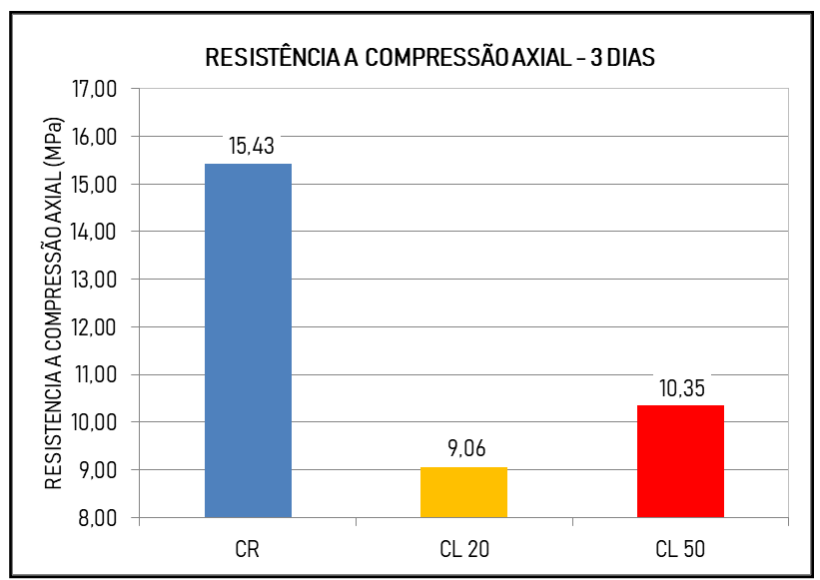

FIGURA 6: Resultados da média de resistência à compressão axial aos 3 dias de idade.

FONTE: Autoria Própria

A Tabela 10 e a Figura 7 mostram os resultados da resistência à compressão do concreto na idade de 7 dias após a moldagem. Nesta idade nota-se que o valor da resistência a compressão do concreto laterítico $\mathrm{CL} 20$ superou a do concreto laterítico $\mathrm{CL} 50$, em comparação a idade inicial de 3 dias, percebe-se também que o concreto de referência supera a resistência característica de projeto.
A Tabela 11 e a Figura 8 mostram os resultados da resistência à compressão do concreto na idade de 28 dias após a moldagem. Em relação a idade de rompimento anterior de 7 dias, Nota-se um pequeno acréscimo de resistência no concreto de referência e uma aproximação dos valores do concreto laterítico $\mathrm{CL}$ 20 e CL 50.

\begin{tabular}{|c|c|c|c|c|}
\hline TRAÇO & $\mathrm{CP}$ & $\begin{array}{c}\text { RESISTÊNCIA A } \\
\text { COMPRESSÃO (MPa) }\end{array}$ & $\begin{array}{c}\text { RESISTÊNCIA A COMPRESSÃO - } \\
\text { MÉDIA ARITIMÉTICA (MPa) }\end{array}$ & $\begin{array}{l}\text { DESVIO } \\
\text { PADRÃO }\end{array}$ \\
\hline \multirow{2}{*}{$\begin{array}{r}\text { REFERÊNCIA - CR } \\
(100 \% \text { BASALTO })\end{array}$} & CP 1 & 21.47 & \multirow{2}{*}{22.71} & \multirow{2}{*}{1.75} \\
\hline & CP 2 & 23.95 & & \\
\hline \multirow{2}{*}{$\begin{array}{c}\text { CONCRETO LATERÍTICO CL } 20 \text { (80\% } \\
\text { BASALTO / 20\% LATERITA) }\end{array}$} & CP 1 & 16.02 & \multirow{2}{*}{16.72} & \multirow{2}{*}{0.99} \\
\hline & CP 2 & 17.42 & & \\
\hline \multirow{2}{*}{$\begin{array}{l}\text { CONCRETO LATERÍTICO CL } 50 \text { (50\% } \\
\text { BASALTO / 50\% LATERITA) }\end{array}$} & CP 1 & 11.21 & \multirow{2}{*}{11.36} & \multirow{2}{*}{0.21} \\
\hline & CP 2 & 11.51 & & \\
\hline
\end{tabular}

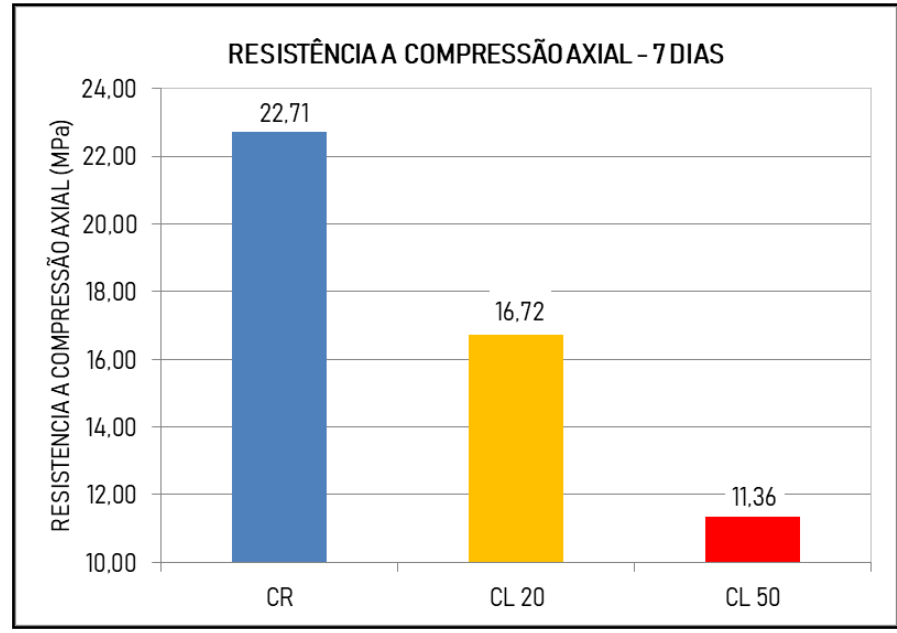

FIGURA 7: Resultados da média de resistência à compressão axial aos 7 dias de idade. FONTE: Autoria Própria. 


\begin{tabular}{|c|c|c|c|c|}
\hline TRAÇO & $\mathrm{CP}$ & $\begin{array}{c}\text { RESISTÊNCIA A } \\
\text { COMPRESSÃO (MPa) }\end{array}$ & $\begin{array}{c}\text { RESISTÊNCIA A COMPRESSÃO - } \\
\text { MÉDIA ARITIMÉTICA (MPa) }\end{array}$ & $\begin{array}{l}\text { DESVIO } \\
\text { PADRÃO }\end{array}$ \\
\hline \multirow{2}{*}{$\begin{array}{l}\text { REFERÊNCIA - CR } \\
(100 \% \text { BASALTO) }\end{array}$} & $\mathrm{CP} 1$ & 22.79 & \multirow{2}{*}{23.83} & \multirow{2}{*}{1.47} \\
\hline & $\mathrm{CP} 2$ & 24.87 & & \\
\hline \multirow{2}{*}{$\begin{array}{c}\text { CONCRETO LATERÍTICO CL } 20 \text { (80\% } \\
\text { BASALTO / 20\% LATERITA) }\end{array}$} & $\mathrm{CP} 1$ & 17.34 & \multirow{2}{*}{17.95} & \multirow{2}{*}{0.86} \\
\hline & $\mathrm{CP} 2$ & 18.56 & & \\
\hline \multirow{2}{*}{$\begin{array}{l}\text { CONCRETO LATERÍTICO CL } 50 \text { (50\% } \\
\text { BASALTO / 50\% LATERITA) }\end{array}$} & $\mathrm{CP} 1$ & 15.89 & \multirow{2}{*}{15.71} & \multirow{2}{*}{0.25} \\
\hline & $\mathrm{CP} 2$ & 15,53 & & \\
\hline
\end{tabular}

FONTE: Autoria Própria

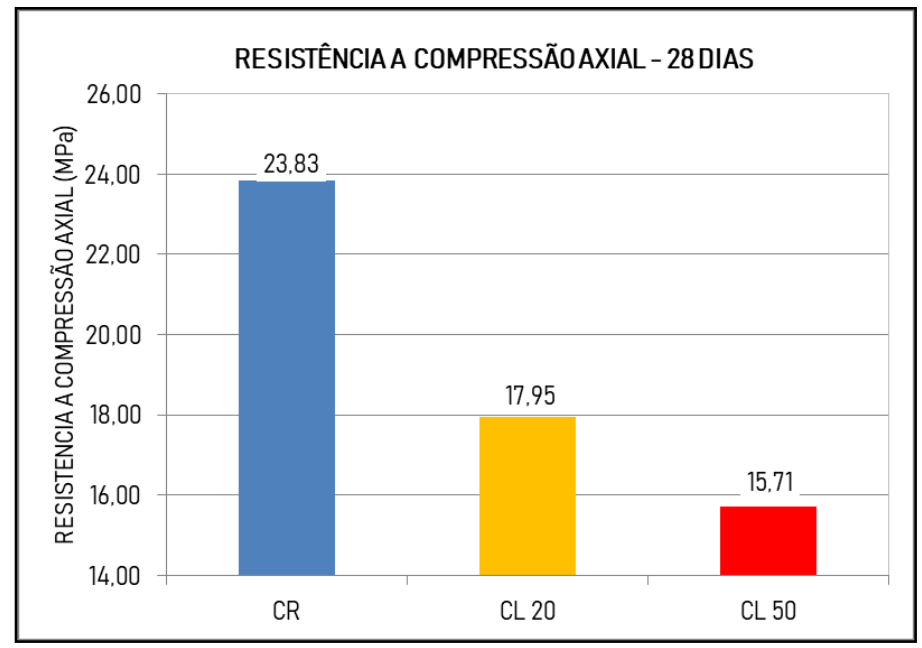

FIGURA 8: Resultados da média de resistência à compressão axial aos 28 dias de idade.

FONTE: Autoria Própria

O gráfico da Figura 9 apresenta o comparativo dos resultados da resistência à compressão axial do concreto nas idades de 03, 07 e 28 dias após a moldagem.

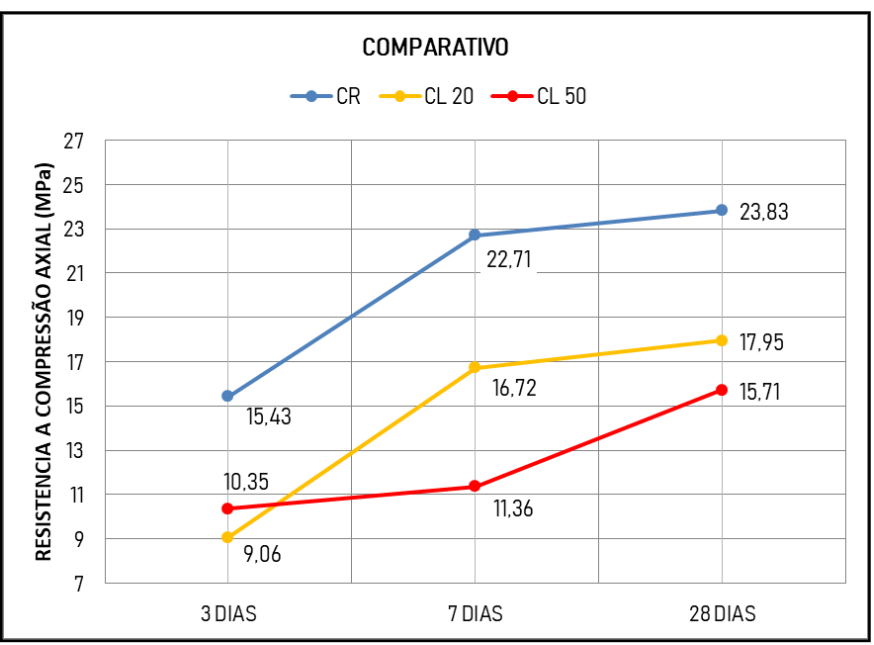

FIGURA 9: Comparativo de resistência à compressão axial aos 3, 7 e 28 dias de idade.

FONTE: Autoria Própria 


\subsubsection{Resistência a tração por compressão diametral}

Foram moldados corpos-de-prova cilíndricos de $10 \times 20 \mathrm{~cm}$ e rompidos nas idades de 28 dias da data de moldagem. Os ensaios de resistência à tração por compressão diametral seguiram conforme a NBR 7222 (ABNT, 2011). A figura 33 mostra o rompimento dos CP's. A prensa utilizada é da marca SOLOTEST, com capacidade de carga máxima de 200 KN. A Tabela 12 e a Figura 10 mostram os resultados da resistência à tração por compressão diametral. No comparativo da resistência a tração por compressão diametral a dosagem que mais se assemelha ao concreto convencional é a CL-20 $(80 \%$ de basalto e $20 \%$ de laterita), atingindo $87,37 \%$ da resistência a tração aos 28 dias de idade do concreto.

\subsubsection{Módulo de elasticidade}

A Tabela 13 e a Figura 11 mostram os resultados do módulo de elasticidade na idade de 28 dias estimado de acordo com a NBR 6118 (ABNT, 2014). Segundo esta norma, o módulo de deformação longitudinal depende da resistência à compressão do concreto $(f c)$.

Neste experimento pôde-se observar que o módulo de elasticidade $(E)$ calculado do concreto laterítico CL 20 e CL 50 assumem valores aproximados.

\begin{tabular}{|c|c|c|}
\hline \multicolumn{2}{|c|}{ Tabela 12: Resultados da resistência a tração por compressão diametral aos 28 dias de idade. } \\
\hline TRAÇO & FORÇA MÁXIMA (Kgf) & RESISTÊNCIA A TRAÇÃO (MPa) \\
\hline $\begin{array}{c}\text { REFERENCIA - CR } \\
(100 \% \text { BASALTO) }\end{array}$ & 9.210 & 2.93 \\
\hline $\begin{array}{c}\text { CONCRETO LATERÍTICO CL 20 } \\
\text { (80\% BASALTO / 20\% LATERITA) }\end{array}$ & 8.060 & 2.56 \\
\hline $\begin{array}{c}\text { CONCRETO LATERÍTICO CL 50 } \\
\text { (50\% BASALTO / 50\% LATERITA) }\end{array}$ & 7.210 & 2.29 \\
\hline
\end{tabular}

FONTE: Autoria Própria

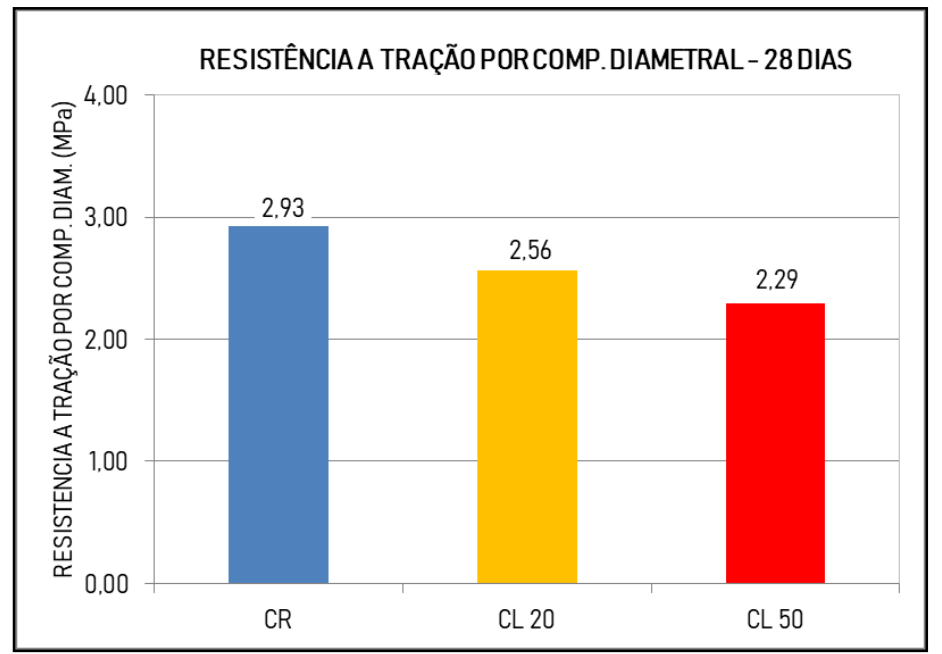

Figura 10: Resultados a tração por compressão diametral aos 28 dias de idade. 


\begin{tabular}{|c|c|c|}
\hline \multicolumn{3}{|c|}{ Tabela 13: Módulo de elasticidade (E) calculado aos 28 dias de idade. } \\
\hline TRAÇO & $\begin{array}{c}\text { RESISTÊNCIA A } \\
\text { COMPRESSÃO (MPa) }\end{array}$ & $\begin{array}{c}\text { MÓDULO DE ELASTICIDADE } \\
- \text { E (GPa) }\end{array}$ \\
\hline $\begin{array}{c}\text { REFERÊNCIA - CR } \\
\text { (100\% BASALTO) }\end{array}$ & 23.83 & 27.33 \\
\hline $\begin{array}{c}\text { CONCRETO LATERÍTICO - CL 20 (80\% } \\
\text { BASALTO / 20\% LATERITA) }\end{array}$ & 17.95 & 23.72 \\
\hline $\begin{array}{c}\text { CONCRETO LATERÍTICO - CL 50 } \\
\text { (50\% BASALTO / 50\% LATERITA) }\end{array}$ & 15.71 & 22.19 \\
\hline
\end{tabular}

FONTE: Autoria Própria

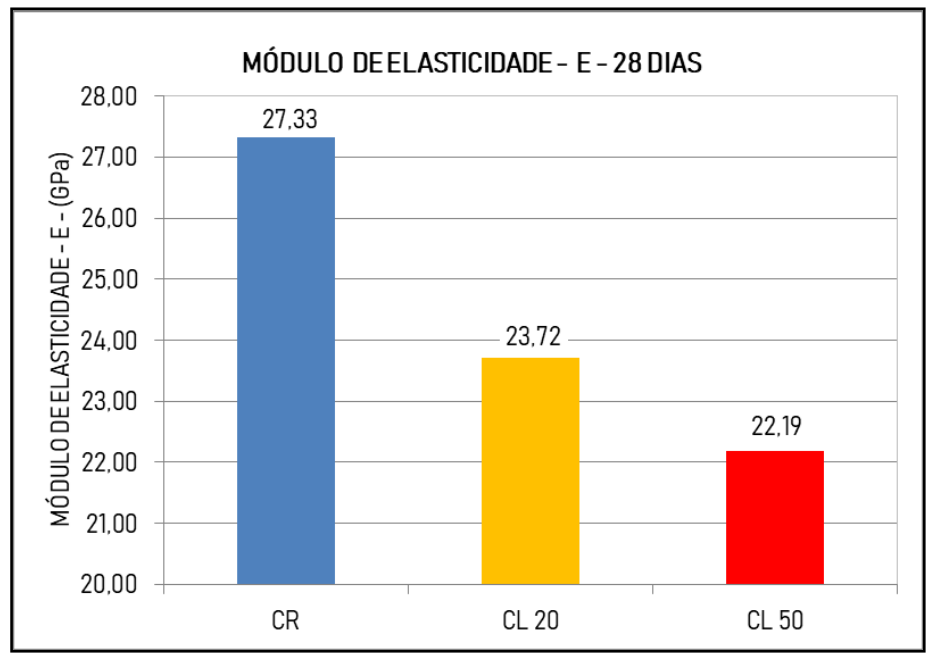

Figura 11: Módulo de elasticidade (E) calculado aos 28 dias de idade.

FONTE: Autoria Própria

\section{CONCLUSÕES}

No ensaio de determinação do material pulverulento verificou-se que a quantidade deste material é bem superior no agregado graúdo laterítico em relação ao agregado graúdo de brita basáltica e cerca de quatorze vezes acima do limite estabelecido na norma ABNT NBR 7211:2009, o que faz com que os concretos produzidos com laterita consumam mais água. Acima de determinado teor de substituição, o concreto torna-se inviável economicamente, pois há a necessidade de um grande aumento na quantidade de aditivo para se manter a consistência desejada. A resistência e o módulo de elasticidade do concreto diminuíram em função dos acréscimos efetuados nos teores de substituição. Os Traços CL 20 e CL 50,
Apresentaram redução na resistência a compressão axial de cerca de $29 \%$ em relação ao concreto de referência aos 28 dias de idade. As duas misturas incorporadas com agregado laterítico se mostraram muito semelhantes, após os 28 dias, no que se refere a ganhos de resistência a compressão simples, apesar da grande diferença nas proporções de agregado graúdo substituído. A análise do estudo mostra um potencial do concreto incorporado com substituição parcial de agregado graúdo basáltico por laterita em seu estado natural. No entanto apesar de apresentar resultados satisfatórios, sugere-se análise mais rigorosa do ponto de vista da durabilidade e econômico, com a finalidade de proporcionar a redução dos custos da produção, haja a vista a grande necessidade em se acrescentar na mistura aditivo plastificante se obter a trabalhabilidade desejada. 


\section{REFERÊNCIAS BIBLIOGRÁFICAS}

Associação Brasileira de Normas Técnicas. NBR NM 33 Concreto - Amostragem de concreto fresco. Rio de Janeiro, 1998.

NBR NM 67: Concreto - Determinação da consistência pelo abatimento do tronco de cone. Rio de Janeiro, 1998.

NBR NM 27: Agregados - Redução da amostra de campo para ensaios de laboratório. Rio de Janeiro, 2001.

NBR NM 51: Agregado graúdo - Ensaio de abrasão “Los Ángeles”. Rio de Janeiro, 2001.

NBR NM 248: Agregados - Determinação da composição granulométrica. Rio de Janeiro, 2003.

NBR NM 46 - Agregados - Determinação do material fino que passa através da peneira $75 \mu \mathrm{m}$, por lavagem. Rio de Janeiro, 2003.

NBR NM 45 - Agregados - Determinação da massa unitária e do volume de vazios. Rio de Janeiro, 2006.

NBR NM 26 - Agregados - Amostragem. Rio de Janeiro, 2009.

NBR 7211 - Agregados para concreto Especificação. Rio de Janeiro, 2009.

NBR NM 52 - Agregado miúdo - Determinação da massa específica e massa especifica aparente. Rio de Janeiro, 2009.

NBR NM 53 - Agregado graúdo - Determinação da massa específica, massa especifica aparente e absorção de água. Rio de Janeiro, 2009.

NBR NM 7218 - Agregados - Determinação do teor de argila em torrões e materiais friáveis. Rio de Janeiro, 2010.

NBR 7222 - Concreto e argamassa Determinação da resistência à tração por compressão diametral de corpos-de-prova-cilíndricos. Rio de Janeiro, 2011.

NBR 6118 - Projeto de estruturas de concreto -Procedimento. Rio de Janeiro, 2014.

NBR 12655 - Concreto de cimento Portland Preparo, controle, recebimento - Procedimento. Rio de Janeiro, 2015

NBR 5738 - Concreto - Procedimento para moldagem e cura de corpos-de-prova. Rio de Janeiro, 2016.
ABNT - Associação Brasileira de Normas Técnicas. NBR 16697 - Cimento Portland - Requisitos. Rio de Janeiro, 2018.

ABNT - Associação Brasileira de Normas Técnicas. NBR 5739 - Concreto - Ensaios de compressão de corposde-prova cilíndricos. Rio de Janeiro, 2018.

ABNT - Associação Brasileira de Normas Técnicas. NBR 7809 - Agregado graúdo - Determinação do índice de forma pelo método do paquímetro - Método de ensaio. Rio de Janeiro, 2019.

ARAÚJO, R. B. Estudo das concreções lateríticas de Tocantins como agregado graúdo na fabricação de concreto de cimento Portland destinado a pavimentação rodoviária - Tese (Mestrado em Engenharia civil e ambiental) - Universidade Federal da Paraíba, Centro de Tecnologia e Recursos Naturais. Campina Grande, 2009;

ALMEIDA GONZALES, A.C. Concreto com agregado graúdo lateritico proveniente do Município de Estreito do Estado do Maranhão. - Tese (Mestrado em Processos Construtivos e Saneamento Urbano) Universidade Federal do Pará, Belém/PA, 2018;

BOGGIO, A. J.. Estudo comparativo de métodos de dosagem de concretos de cimento Portland. - Tese (Mestrado em Engenharia Civil) - Universidade Federal do Rio Grande do Sul, Porto Alegre/RS, 2000.

CHAGAS FILHO, M. B.. Estudo de agregados lateríticos para utilização em concretos estruturais. - Tese (Doutorado em Engenharia de Processos) Universidade Federal de Campina Grande, Centro de Ciências e Tecnologia. Campina Grande, 2005;

DE LUCA NETO, L..A.. Propriedades mecânicas do concreto laterítico da região do Acre . - Tese (Mestrado em Processos Construtivos e Saneamento Urbano) - Universidade Federal do Pará, Belém/PA, 2014;

FALCÃO BAUER, L.A.; Materiais de construção - Novos materiais para construção civil. 5.ed. Rio de Janeiro, LTC, 2008.

HELENE, P.R.L.; TERZIAN, P. Manual de dosagem e controle do concreto, I. ed. São Paulo, PINI, 1993.

MEHTA, P.K.; MONTEIRO, P.J.M. Concreto: microestrutura, propriedades e materiais. Tradução da 3. ed. em inglês. São Paulo: Ibracon, 2008. 674 p

MELFI, A. J. Lateritas e processos de laterização. Publicação 93. Escola de Engenharia de São Carlos. USP. 29p. 1997. 
MOIZINHO, J. C..Caracterização e uso de agregados lateriticos do Distrito Federal e do Estado de Roraima em CBUQ . - Tese (Doutorado em Geotecnia) Universidade Federal de Brasilia, DF, 2007.

MIELI, P. H.. Avaliação do tijolo modular de solocimento como material na construção civil. - Tese (Conclusão de curso de Engenharia de Materiais) Universidade Federal do Rio de Janeiro, Rio de janeiro/RJ, 2009.

MOREIRA, A. R. Apostila de Tecnologia do Concreto. CEFET-PR, 2004.

NEVILLE, A. M. Propriedades do Concreto. Tradução Salvador E. Giamamusso, 2a ed. São Paulo, PINI, 1997.

TARTUCE, R.; GIOVANNETTI, E. Princípios básicos sobre o concreto de cimento Portland, 1a ed. São Paulo, PINI: IBRACON, 1990. 